\title{
Comparison of Ex-Situ and In-Situ Transesterification for the Production of Microbial Biodiesel
}

\author{
Alia Tasnim Hazmi ${ }^{1}$, Farah B. Ahmad ${ }^{1,2, *}$, Ahdyat Zain Athoillah ${ }^{1,3}$, Ahmad Tariq Jameel1,4 \\ ${ }^{1}$ Department of Biotechnology Engineering, Kulliyyah of Engineering, International Islamic University \\ Malaysia, Kuala Lumpur, Malaysia. \\ ${ }^{2}$ Department of Mechanical Engineering, Faculty of Engineering, University of Malaya, Kuala Lumpur \\ 50603, Malaysia. \\ ${ }_{3}^{3}$ Department of Transdisciplinary Science and Engineering, School of Environment and Society, Tokyo \\ Institute of Technology, Japan. \\ ${ }_{4}^{4}$ Department of Chemical Engineering, Aligarh Muslim University, Aligarh 202002, India.
}

Received: 22 $2^{\text {nd }}$ May 2021; Revised: 30th July 2021; Accepted: $2^{\text {nd }}$ August 2021

Available online: 14th August 2021; Published regularly: December 2021

\section{Abstract}

Microbial biodiesel is converted from microbial lipids via transesterification process. Most microbial biodiesel studies are focusing on the use of microalgal lipids as feedstock. Apart from using microalgae for lipid biosynthesis, lipids can also be extracted from other oleaginous microorganisms like fungi and yeast. However, there are gaps in the studies of lipid production from filamentous fungi, especially in-situ transesterification process. The aim of this project is to compare in-situ with the ex-situ transesterification of fungal biomass from Aspergillus oryzae. In exsitu transesterification, two methods of lipid extraction, the Soxhlet extraction and the Bligh and Dyer extraction, were performed. For in-situ transesterification, two methods using different catalysts were investigated. Basecatalyzed in-situ transesterification of fungal biomass resulted on the highest Fatty Acid Methyl Esters (FAME) yield. The base-catalyzed in-situ transesterification was further optimized via Central Composite Design (CCD) of Response Surface Methodology (RSM). The parameters investigated were the catalyst loading, methanol to biomass ratio and reaction time. The optimization showed that the highest FAME yield was at $25.1 \%(w / w)$ with 10 minutes reaction time, 5\% catalyst and 360:1 of the ratio of the methanol to biomass. Based on Analysis of Variance (ANOVA), the model was found to be significant according to the value of "Prob $>F$ " of 0.0028 .

Copyright (C 2021 by Authors, Published by BCREC Group. This is an open access article under the CC BY-SA License (https://creativecommons.org/licenses/by-sa/4.0).

Keywords: Aspergillus; Biodiesel; Ex-situ transesterification; In-situ transesterification; Lipid; Solvent extraction

How to Cite: A.T. Hazmi, F.B. Ahmad, A.Z. Athoillah, A.T. Jameel (2021). Comparison of Ex-Situ and In-Situ Transesterification for the Production of Microbial Biodiesel. Bulletin of Chemical Reaction Engineering \& Catalysis, 16(4), 733-743 (doi:10.9767/bcrec.16.4.11044.733-743)

Permalink/DOI: https://doi.org/10.9767/bcrec.16.4.11044.733-743

\section{Introduction}

As the world's population and economy continue to rise and expand, the energy consumption around the world increases. The energy consumption is mainly sourced from fossil fuels, making up to $80 \%$ of global energy consumption

\footnotetext{
* Corresponding Author.

Email: farahahmad@iium.edu.my (F.B. Ahmad)
}

[1]. The main concern with the reliance on fossil fuels, are the resulting global warming and the depletion of fossil fuels with time. Apart from that, the formation of fossil fuels requires millions of years and the usage of fossil fuels causes environmental pollution [2]. Due to the overwhelming increase in petrol fuels demand globally, the search for alternatives fuels is critical to avoid the scarcity of fuel source. Biodiesel, as 
an alternative to fossil fuels, can be utilized as vehicle fuel without major modification in diesel engine [3,4]. Biodiesel is the most promising alternative for vehicle fuel as studies reported that biodiesel is environmentally friendly, easily biodegradable and renewable [5,6].

Biodiesel is one of the renewable energies that is being produced through transesterification of triacylglycerols into fatty acid alkyl esters (biodiesel). Throughout the years, biodiesel production continued to be evolved until the discovery of microbial biodiesel red. Microbial biodiesel is produced from lipids extracted from the biomass of oleaginous microorganisms, such as: bacteria, fungi, microalgae and yeasts [7]. Before lipid can be extracted from the microbial biomass, the cell wall of the microorganisms must be broken down to release the lipids accumulated inside the cell either by using mechanical, solvent, chemical and enzymatic extraction methods [8-11]. In the overall process of biodiesel production, the extraction step is the most crucial part to guarantee an efficient biodiesel production [12]. The lipid undergoes the process of transesterification where triacylglycerides (TAG) is converted into fatty acid methyl esters (FAMEs) and glycerol from using methanol and acidic or basic catalyst [13].

Among all the microorganisms listed as the suitable candidates for oleaginous microorganisms, microalgae are the most well-known microorganisms that have been reported. Microalgae possessed the ability to synthesize lipid with up to 20 to $50 \%$ of dry weight. However, the cell walls of microalgae are hard to be disrupted, making it one of the challenges in extracting the lipids [14]. However, the studies on microbial biodiesel production from nonmicroalga culture are limited. This project aims to focus on the biodiesel obtained from fungi, specifically Aspergillus oryzae. Oleaginous fungi also have potential in biodiesel production as fungi was reported to produce lipid that can be further converted into biodiesel [15]. However, the studies on lipid extraction from fungi biomass are scarce. Fungi biomass is slightly different than microalgae biomass as fungal cell is composed of more rigid cell wall [8].

This study focuses on investigating the most efficient transesterification process by comparing between ex-situ transesterification and insitu transesterification. In-situ (direct) transesterification could potentially reduce the processing cost and overall reaction time of conventional ex-situ transesterification. The main aim of this study is to optimize the yield microbial biodiesel through comparison between the transesterification processes (one-factor-at-atime study on the extraction method and the type of solvent), followed by optimizing the transesterification process (Response Surface Methodology study) that was more effective. The optimization study was based on three parameters, which were catalyst loading, ratio of methanol to biomass and reaction time during the transesterification process. The outcome of this study could potentially improve the microbial lipid extraction efficiency for sustainable production of microbial biodiesel from fungal biomass.

\section{Materials and Methods}

\subsection{Fungal Cultivation}

Aspergillus oryzae fungal strain was obtained from UKM Culture Collection Center, Malaysia. The cultivation was conducted at $180 \mathrm{rpm}$ and $28^{\circ} \mathrm{C}$. The cultivation media was prepared based on Ahmad et al. [15]. The biomass was harvested from the culture flask after 7 days of cultivation and dried in oven for overnight at $105{ }^{\circ} \mathrm{C}$. Figure 1 depicts overall methodology undertaken in this study for microbial biodiesel production from fungal lipid.

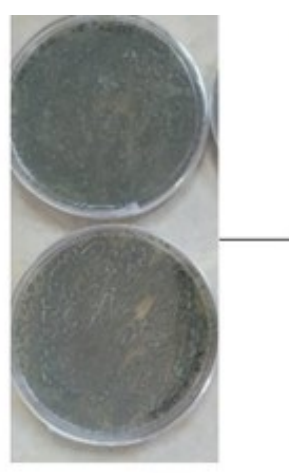

Fungi Aspergillus oryzae

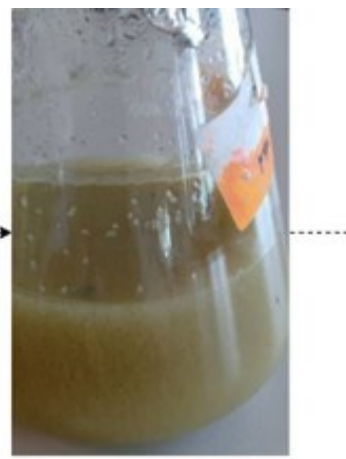

Mierobial cultivation

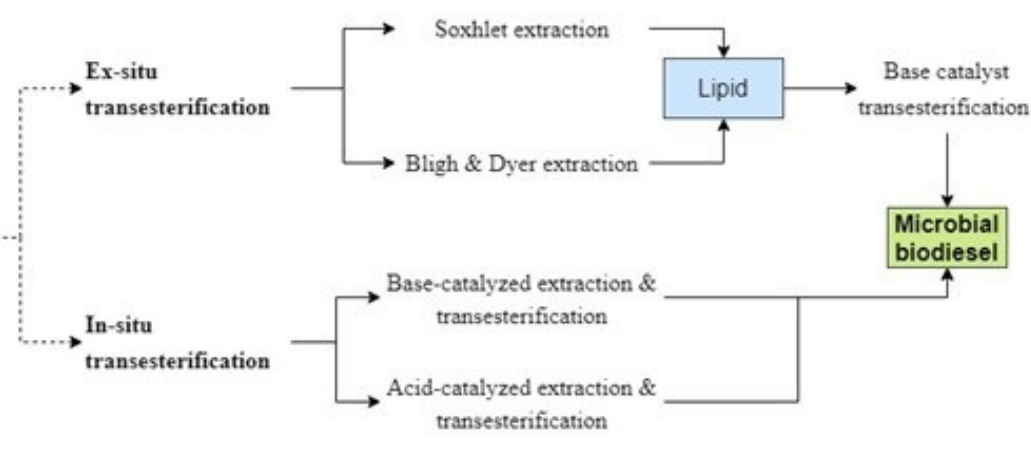

Figure 1. Overall process for the production of microbial biodiesel from fungal lipid. 


\subsection{Bligh and Dyer Extraction Method}

This method was established to extract lipid from marine biomass via solvent extraction using methanol and chloroform [16,17]. Fungal biomass harvested was mixed with chloroform, methanol and water (1:2:0.8 ratio). The biomass was sonicated for one hour to completely break the lump of biomass. After sonicating the biomass, the mixture was vacuum filtered using the Whatman No 1 filter paper. Before the mixture was filtered, few drops methanol was placed onto the filter paper to make it wet. The mixture was then poured onto the filter paper and left until the biomass was completely dried. The lipid-containing solvent (filtrate) was then transferred into a glass tube and left to dry at $60^{\circ} \mathrm{C}$.

\subsection{Soxhlet Extraction Method}

In this method, biomass was mixed with hexane as extraction solvent [18]. The mixture was sonicated using the sonicator to mechanically shear the microstructure of the biomass [18]. The biomass was then transferred into the cellulose extraction thimble. The thimble was then placed inside the extraction chamber as shown in Figure 2. Approximately $40 \mathrm{~mL}$ of

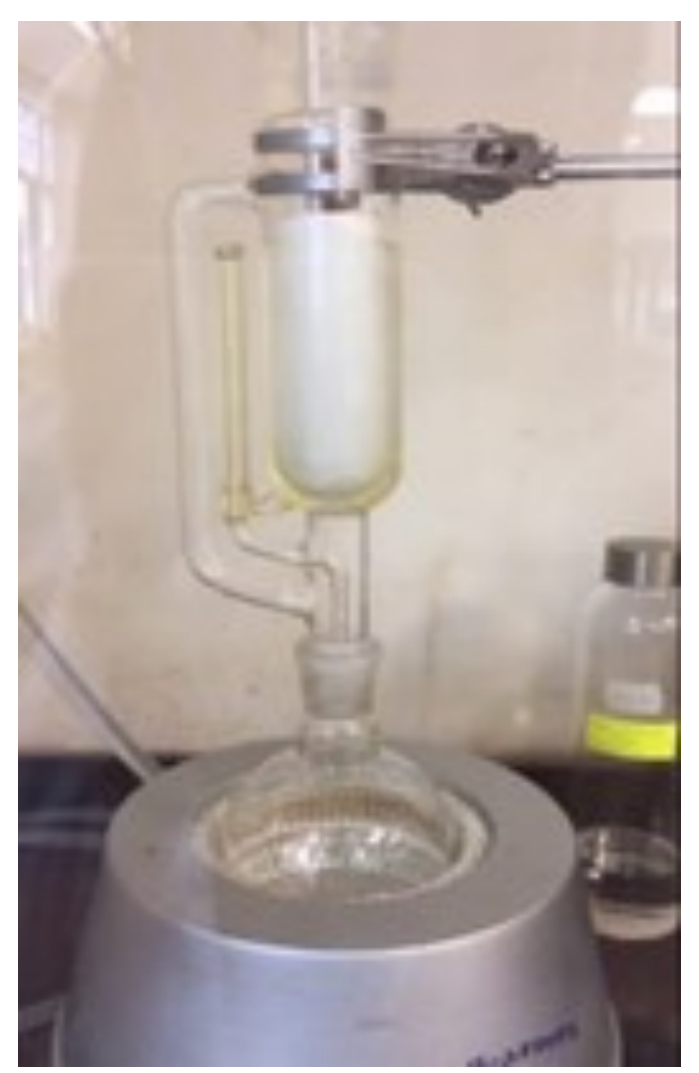

Figure 2. The experimental setup of the Soxhlet extraction method. hexane as extraction solvent was poured into the boiling flask. It was refluxed over the thimbles for about $3 \mathrm{~h}$. After that, the lipidcontaining solvent in the boiling flask was collected and poured into a glass tube. The tube was then heated at $60^{\circ} \mathrm{C}$ until the solvent completely dried and only the lipid remained in the tube.

\subsection{Ex-situ Transesterification Process}

After the lipid had been extracted from the biomass, transesterification process was performed to produce biodiesel from the lipid. The lipid transesterification method used in this project was modified from the study by Zhang et al. [19]. The lipid in hexane solution at 25 $\mathrm{mL} / \mathrm{g}$ (hexane/lipid) was added with methanol (ratio of lipid to methanol $=1: 6$ ). The catalyst used in this process was $1 \%(w / w) \mathrm{NaOH} /$ lipid. The mixture was then left for $2 \mathrm{~h}$ at $55{ }^{\circ} \mathrm{C}$ to allow the reaction to occur. After the addition of $5 \%(w / v) \mathrm{NaCl}$ solution, the extracted FAME was washed using hexane for two times. The mixture was then allowed to settle into two different phases before the upper layer which contained FAME and hexane was collected. The collected layer was then washed using $2 \%$ $(w / v)$ sodium bicarbonate solution. The mixture was left for 15 minutes to allow phase separation to occur and the upper layer containing hexane and FAME was collected and dried at $60{ }^{\circ} \mathrm{C}$. FAME yield was calculated using Eq. (1).

FAME yield $(\%)=\frac{\text { FAME extracted }(g)}{\text { mass of biomass used }(g)} \times 100$

\subsection{Base-Catalyzed In-Situ Transesterification Using Sonification}

The method for in-situ transesterification using base catalyst was based on method done by Zhang et al. [19]. The dry biomass was mixed with methanol and $5 \%(w / w) \mathrm{NaOH}$ (NaOH/lipid) [19]. Hexane as co-solvent was added into the tube for $2.5 \mathrm{~mL}$ [19]. The mixture was then sonicated for $30 \mathrm{~min}$, followed by the addition of $0.1 \mathrm{~mL}$ of $5 \%(w / v) \mathrm{NaCl}$ solution [19]. FAME extraction was done by performing washing using $1 \mathrm{~mL}$ hexane for two times. The mixture was centrifuged for 20 minutes at $9000 \mathrm{rpm}$ to separate the biomass from the hexane layer. The residual that was not separated during centrifugation was then separated by filtration. The filtrate was collected for phase separation, where the top layer, that contained hexane and FAME, was extracted and dried at $60^{\circ} \mathrm{C}$. 


\subsection{Acid-Catalyzed In-Situ Transesterification}

$\mathrm{HCl}$ was used in acid-catalyzed in-situ method [20]. $0.1 \mathrm{~g}$ biomass was pre-soaked with mixture of $0.2 \mathrm{~mL}$ methanol/chloroform $(2: 1$ $v / v)$, followed by the addition of $0.3 \mathrm{~mL}$ $\mathrm{HCl} /$ methanol $(5 \% v / v)$ [20]. The mixture was heated at $85{ }^{\circ} \mathrm{C}$ for $1 \mathrm{~h}$. After the reaction, 9 $\mathrm{mL}$ of hexane was added into the beaker and left for $1 \mathrm{~h}$ to allow FAME to dissolve into the hexane layer. The upper layer was then extracted and dried at $60^{\circ} \mathrm{C}$.

\subsection{Optimization of In-Situ Transesterification}

In the previous section, two types of transesterification process (in-situ and ex-situ transesterification) and different solvent systems were tested, in which the process with the highest microbial biodiesel would be further investigated in the optimization study in this section.

Base-catalyzed in-situ transesterification was further investigated in optimization study as the transesterification process resulted on better yield of microbial biodiesel than acidcatalyzed in-situ transesterification and ex-situ transesterification. Table 1 shows the parameters to be optimized (independent variables) were catalyst loading, methanol to biomass ratio and reaction time. By using Design Expert 6.0.8, the optimization experiment was designed based on face-centered central composite design (FCCCD) of Response Surface Methodology (RSM) with three center points. The response (dependent variable) for the optimization experiment was FAME yield.

\section{Results and Discussion}

3.1 Microbial Biodiesel Production via Extraction and Ex-Situ Transesterification of Fungal Biomass

In this study, two transesterification processes (ex-situ transesterification and in-situ transesterification) using homogeneous catalysts were investigated that entailed two different extraction process with different solvent/catalyst systems. Homogeneous catalysts that are commonly used for transesterification process are acid or base catalyst.
The experiments for ex-situ transesterification were performed in this study with different extraction methods and different solvent systems. The extraction methods chosen were the Bligh and Dyer extraction (methanol, chloroform and water (2:1:0.8) as the solvents) and the Soxhlet extraction (hexane as the extraction solvent). The methods were compared through the results of the lipid yield and fatty acid methyl esters (FAMEs) yield that were produced at the end of the experiments. Exsitu transesterification from the Soxhlet extraction resulted on lipid concentration, lipid yield and FAME yield of $10.25 \mathrm{~g} / \mathrm{L}, 20.50 \%$ $(w / w)$ and $14.21 \%(w / w)$ respectively, whereas the lipid concentration, lipid yield and FAME yield of transesterification from the Bligh and Dyer extraction method was $11.88 \mathrm{~g} / \mathrm{L}, 23.75 \%$ $(w / w)$ and $16.46 \%(w / w)$ respectively.

The yield for the lipid shows minor difference between the Soxhlet and the Bligh and Dyer extraction with the former having $20.5 \%$ yield compared to the latter with the yield of $23.75 \%$. This shows that extraction solvents influenced the lipid yield. This is due to the extraction solvents of chloroform, methanol and water is a mixture of non-polar and polar solvents whereas hexane is a non-polar solvent. Non-polar solvents can only dissolve non-polar lipids [21]. The mixture of methanol, a polar solvent, and chloroform, a non-polar solvent, was shown to be more efficient in extracting lipids that are both neutral and polar [21]. From the results of both experiments, it can be concluded that using polar and non-polar solvent mixture in extracting the lipids could improve the lipid yield and subsequently increase the FAME yield during the transesterification process. Although the FAME yield from both transesterification gave slight difference, it will greatly affect the yield once the process has been scaled up, which subsequently will have massive impact on the economics of microbial biodiesel production. By choosing in-situ transesterification, the overall operation cost of the process can be reduced.

Table 2 compares lipid yields extracted via the Soxhlet and the Bligh and Dyer extraction methods from dry biomass of various oleaginous microorganisms. The findings from previ-

Table 1. The parameters (independent variables) and range used in RSM experimental design.

\begin{tabular}{lcccc}
\hline \multirow{2}{*}{ Parameters } & \multirow{2}{*}{ Notation } & Units & \multicolumn{2}{c}{ Range } \\
\cline { 4 - 5 } & & min & 10 & 30 \\
Time & $A$ & & $6: 1$ & $360: 1$ \\
Methanol to biomass ratio & $B$ & $\% w / w$ & 1 & 5 \\
Catalyst loading & $C$ & $\%$ & \\
\hline
\end{tabular}




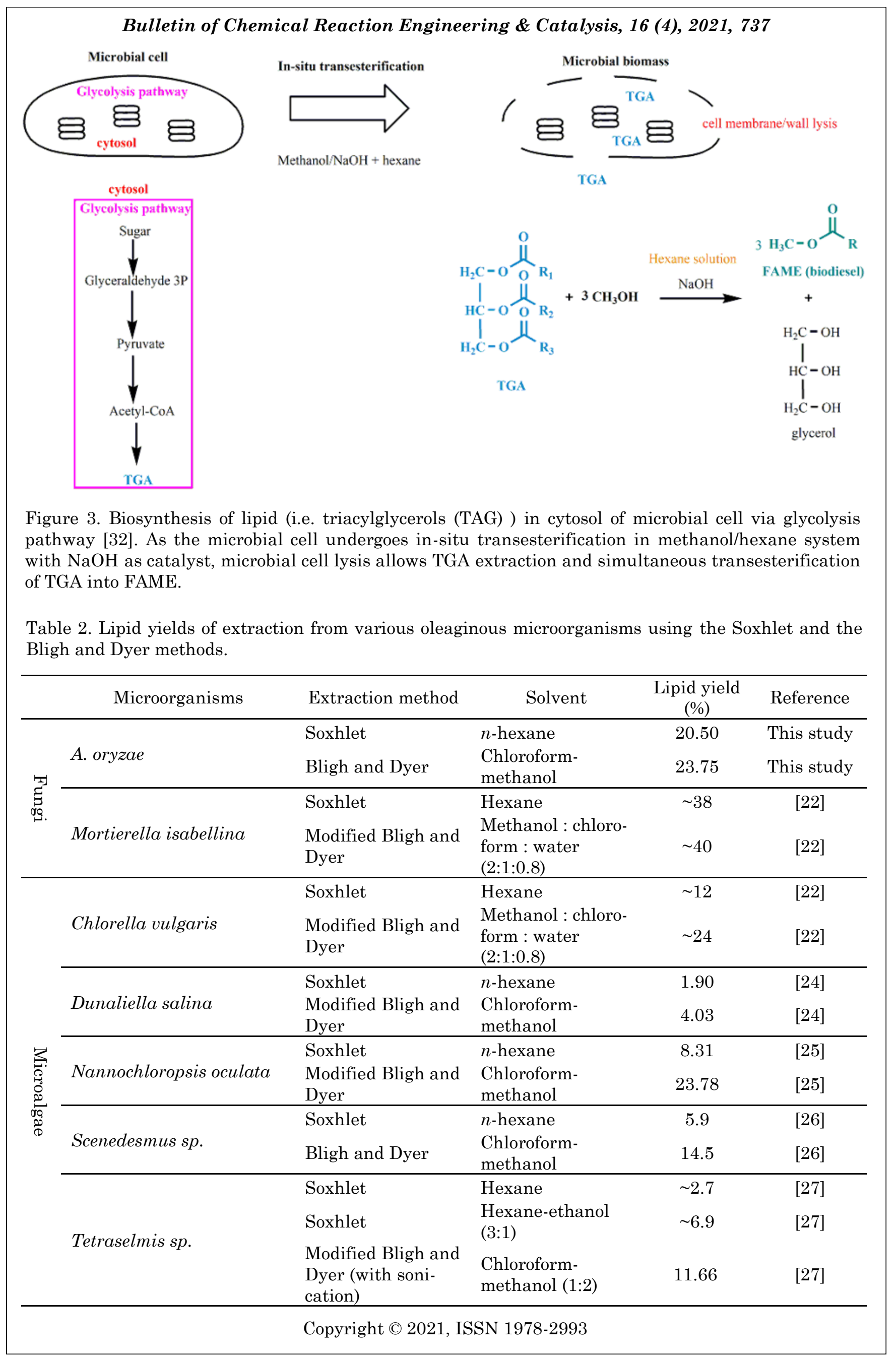


ous studies showed higher lipid yield extracted from the Bligh and Dyer extraction than the Soxhlet extraction method, which was similar to what have been found in this study. There was more substantial difference in lipid yield results between the Soxhlet and the Bligh and Dyer extraction methods in microalgae biomass than fungal biomass.

It could be concluded from Table 2 that appropriate proportions of polar and nonpolar solvents in the extraction of lipid was critical for microalgae biomass. Optimizing lipid extraction from fungi was equally crucial as the method to extract lipids from microbial biomass could be dependent to the types of microorganism. For instance, unlike other unicellular microorganisms including microalgae, fungal cells consist of cell wall which may affect the efficiency of cell disruption method prior to lipid extraction via solvent [8]. The finding from this study was comparable to lipid extraction study from fungi Mortierella isabellina in which the Bligh and Dyer method using chloroform and methanol resulted in slightly better lipid yield than the Soxhlet extraction using single solvent [22].

\subsection{Microbial Biodiesel Production via In-Situ Transesterification of Fungal Biomass}

Microbial lipid is biosynthesized intracellularly within cytosol or endoplasmic reticulum of microbial cell through biochemical pathway of glycolysis pathway [32]. Therefore, it is critical to lyse the cell membrane or cell wall of microorganism through extraction method in order to isolate the microbial lipids (Figure 3). The microbial lipids can further be used for conversion into biodiesel via transesterification. Insitu transesterification process involves the direct conversion of microbial lipid without prior lipid extraction process as per ex-situ trans- esterification. The selection of types of microorganism is crucial as different microorganisms could accumulate different amount lipids. The lipid accumulation could be optimized through optimizing the cultivation media [33], as it will impact glycolysis pathway and microbial growth (subsequently biomass yield). However, this is not the focus of this study as the aim of this study is to optimize the main economic bottleneck for microbial biodiesel production, which is the extraction and transesterification. Figure 3 outlines the overview of in-situ transesterification from lipid (triacyglycerols, TGA), biosynthesized intracellularly via glycolysis pathway, into biodiesel (fatty acid methyl ester, FAME) via simultaneous extraction and transesterification.

The results of in-situ transesterification, reaction catalyzed by $\mathrm{NaOH}$ (base catalyst) and $\mathrm{HCl}$ (acid catalyst) is presented in Table 3. Comparing between the results of FAME yield from both methods (Table 3), the method using base catalyst shows a higher percent yield of FAME than using the acid catalyst.

The reaction of lipids transesterification using the base catalyst was known for its fast reaction compared to the acidic-catalyzed reaction [20]. Several studies reported higher FAME yield from the use of base catalyst in insitu transesterification for microbial biodiesel production (Table 4). The types of catalyst depend on the type of microbial extracellular lipids. Base catalysts are not suitable to be used to convert the free fatty acids. Thus, the yield of FAME in biomass that contained high concentration of free fatty acid could be low [20]. The usage of base catalyst on the biomass that contains large percentage of free fatty acids or water can lead to the formation of soaps and the water will hydrolyse triglycerides into diglycerides, forming additional free fatty acids

Table 3. The yields of lipid and FAMEs for ex-situ and in-situ transesterification.

\begin{tabular}{llccc}
\hline & Extraction method & $\begin{array}{c}\text { Lipid concentration } \\
(\mathrm{g} / \mathrm{L})\end{array}$ & $\begin{array}{c}\text { Lipid yield } \\
(\%, w / w)\end{array}$ & $\begin{array}{c}\text { FAME yield } \\
(\%, w / w)\end{array}$ \\
\hline $\begin{array}{l}\text { Ex-situ trans- } \\
\text { esterification }\end{array}$ & Soxhlet (hexane) & 10.25 & 20.50 & 14.21 \\
& $\begin{array}{l}\text { Bligh and Dyer } \\
\text { (methanol/chloroform) }\end{array}$ & 11.88 & 23.75 & 16.46 \\
& $\begin{array}{l}\text { Base-catalyzed with son- } \\
\text { ication } \\
\text { (methanol/hexane) }\end{array}$ & - & - & 17.9 \\
$\begin{array}{l}\text { In-situ trans- } \\
\text { esterification }\end{array}$ & $\begin{array}{l}\text { Acid-catalyzed } \\
(\text { methanol/chloroform } \\
(2: 1 v / v), \text { hexane) }\end{array}$ & - & - & 3.65 \\
& & & & \\
\hline
\end{tabular}


[23]. However, the use of base catalysts are preferred as it is economical as the process could be done in room temperature and at atmospheric pressure while giving high yield results [24]. The process of in-situ transesterification using base catalyst in this study was carried out at room temperature whereas the method of using acidic catalyst was performed at $85^{\circ} \mathrm{C}$. Apart from that, using hydrochloric acid as the catalyst caused another problem when extracting the hexane layer that contained FAME. The separation and purification process of the product could be more complicated when using acidic catalyst.

In base-catalyzed transesterification, the three reaction processes happened consecutively with the aid of catalyst (Figure 4). The im-

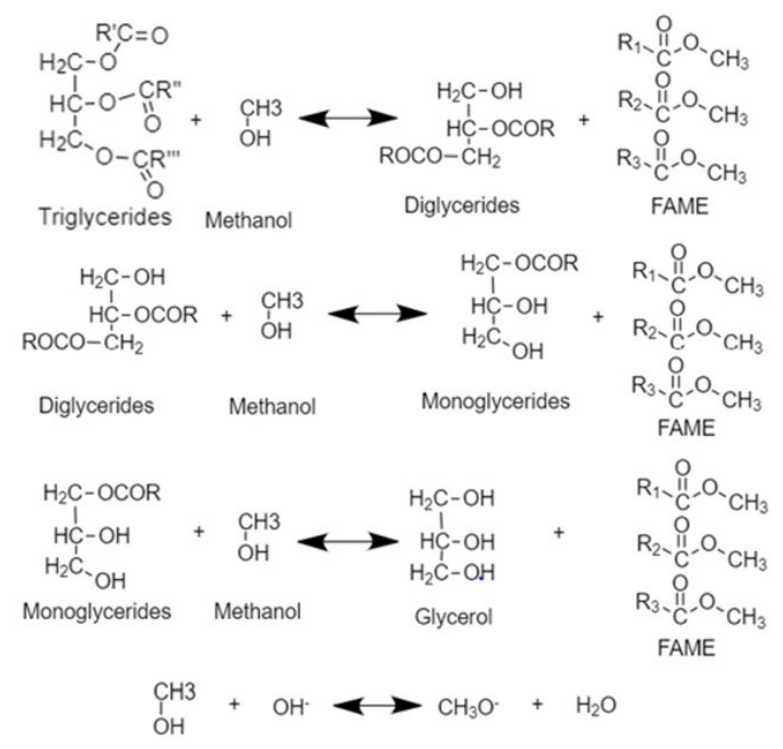

Figure 4. The reactions of producing FAME using base catalyst. portant step of these reactions is the equilibrium of the hydroxide and methoxide, where the methoxide ions will act as the catalyst and the hydroxide ions will be depleted by the nondesired side reactions [28].

3.3 Optimization of In-Situ Transesterification for Microbial Lipid Production from Aspergillus oryzae

The best result from the transesterification process from Table 3 was further optimized for lipid production yield. The optimization study was performed on transesterification method on highest yield of FAME. As previous experiment showed that base-catalyzed in-situ transesterification gave better FAME yield, the transesterification method will be further investigated to determine the optimum parameters by varying catalyst loading, methanol to biomass ratio and reaction time. Table 5 shows the results of the optimization.

The highest FAME yield of $25.1 \%$ was achieved at 10 minutes reaction time, with 5\% of catalyst loading and 360:1 of the ratio of methanol to biomass. From the results of optimization study, the FAME yield showed an increasing pattern as the percent of catalyst increased. For a constant ratio of methanol to biomass at $6: 1$, the yield of FAME increased as the percent of catalyst increased from $1 \%$ to $5 \%$, producing $2.8 \%$ and $20 \%$ of FAME yield. It can be concluded that increasing the catalyst loading could improve the yield of FAME produced as the catalyst increases the rate of reaction between methanol and the lipids. Apart from the catalyst loading, the ratio of methanol to biomass also influenced the result for FAME yield. For $5 \%$ catalyst loading, the FAME yield

Table 4. In-situ transesterification using acid and base catalyst for microbial biodiesel production.

\begin{tabular}{lccc}
\hline \multicolumn{1}{c}{ Extraction method } & Microorganisms & $\begin{array}{c}\text { FAME yield } \\
(\%)\end{array}$ & Ref. \\
\hline $\begin{array}{l}\text { Base-catalyzed with sonication } \\
\text { (methanol/hexane) }\end{array}$ & Aspergillus oryzae & 17.9 & \\
$\begin{array}{l}\text { Acid-catalyzed (methanol/chloroform }(2: 1 \\
v / v) \text {, hexane) }\end{array}$ & Nannochloropsis oculata & $1 \pm 2$ & This study \\
\hline Base-catalyzed $(\mathrm{NaOH})$ & & $8 \pm 2$ & \\
Base-catalyzed $\left(\mathrm{CH}_{3} \mathrm{ONa}\right)$ & Chlorella vulgaris & 6.5 & \\
\hline Base-catalyzed $(\mathrm{NaOH})$ & & 5.8 & \\
Acid-catalyzed (methanol/ $\left.\mathrm{H}_{2} \mathrm{SO}_{4}\right)$ & Maesotaenium caldariorum & 5.6 & \\
\hline Base-catalyzed $(\mathrm{NaOH})$ & & 2.6 & \\
Acid-catalyzed (methanol/ $\left.\mathrm{H}_{2} \mathrm{SO}_{4}\right)$ & & & \\
\hline
\end{tabular}




\section{Bulletin of Chemical Reaction Engineering \& Catalysis, 16 (4), 2021, 740}

Table 5. Results for optimization of in-situ transesterification (base catalyst).

\begin{tabular}{cccccc}
\hline Run & Time (min) & MeOH:biomass & $\begin{array}{c}\text { Catalyst loading } \\
(\% w / w \text { lipid })\end{array}$ & $\begin{array}{c}\text { FAME concentration } \\
(\mathrm{g} / \mathrm{L})\end{array}$ & FAME yield (\%) \\
\hline 1 & 10 & 6 & 1 & 1.4 & 2.80 \\
2 & 10 & 6 & 5 & 2.15 & 4.30 \\
3 & 10 & 120 & 3 & 8.65 & 17.30 \\
4 & 10 & 360 & 5 & 12.55 & 25.10 \\
5 & 10 & 360 & 1 & 9.45 & 18.90 \\
6 & 20 & 6 & 3 & 3.9 & 7.80 \\
7 & 20 & 120 & 5 & 11.9 & 23.80 \\
8 & 20 & 120 & 3 & 8.95 & 17.90 \\
9 & 20 & 120 & 1 & 7.7 & 15.40 \\
10 & 20 & 360 & 3 & 10.55 & 21.10 \\
11 & 20 & 120 & 3 & 8.7 & 17.40 \\
12 & 20 & 120 & 3 & 8.5 & 17.00 \\
13 & 30 & 6 & 1 & 1.45 & 2.90 \\
14 & 30 & 6 & 5 & 10 & 20.00 \\
15 & 30 & 120 & 3 & 11.15 & 22.30 \\
16 & 30 & 360 & 1 & 9.9 & 19.80 \\
17 & 30 & 360 & 5 & 10.7 & 21.40 \\
\hline
\end{tabular}

Table 6. Analysis of variance (ANOVA) for response surface quadratic model of FAME yield.

\begin{tabular}{lccccc}
\hline Source & $\begin{array}{c}\text { Sum of } \\
\text { squares }\end{array}$ & $\begin{array}{c}\text { Degree of } \\
\text { freedom }\end{array}$ & Mean square & $F$-value & $\begin{array}{c}P \text {-value } \\
\text { (Prob }>F)\end{array}$ \\
\hline Model & 776.47 & 9 & 86.27 & 10.25 & 0.0028 \\
$A-$ Time & 26.54 & 1 & 26.54 & 3.16 & 0.1189 \\
$B-$ MeOH:biomass & 469.23 & 1 & 469.23 & 55.77 & 0.0001 \\
$C$-catalyst loading & 113.67 & 1 & 113.67 & 13.51 & 0.0079 \\
$A B$ & 0.84 & 1 & 0.84 & 0.100 & 0.7615 \\
$A C$ & 135.42 & 1 & 135.42 & 16.10 & 0.0051 \\
$B C$ & 0.35 & 1 & 0.35 & 0.041 & 0.8451 \\
$A^{2}$ & 44.47 & 1 & 44.47 & 5.29 & 0.0551 \\
$B^{2}$ & 15.12 & 1 & 15.12 & 1.80 & 0.2219 \\
$C^{2}$ & 15.60 & 1 & 15.60 & 1.85 & 0.2155 \\
Residual & 58.89 & 7 & 8.41 & & \\
Lack of fit & 58.48 & 5 & 11.70 & 57.53 & 0.0172 \\
Pure error & 0.41 & 2 & 0.20 & & \\
Cor total & 835.36 & 16 & & & \\
\hline
\end{tabular}


increased as the ratio increased except when the time of reaction was varied. Comparing between reaction time of 10 minutes and 30 minutes (ratio of methanol to biomass and catalyst loading were constant at $6: 1$ and $5 \%$ respectively), the FAME yield for the latter parameter was $20 \%$ which was much higher than the result at 10 minutes which was only $4.3 \%$.

The result of analysis of variance (ANOVA) on the RSM optimization study is presented in Table 6 and Table 7. The proposed equation for the optimization model is as shown in Equation (2):
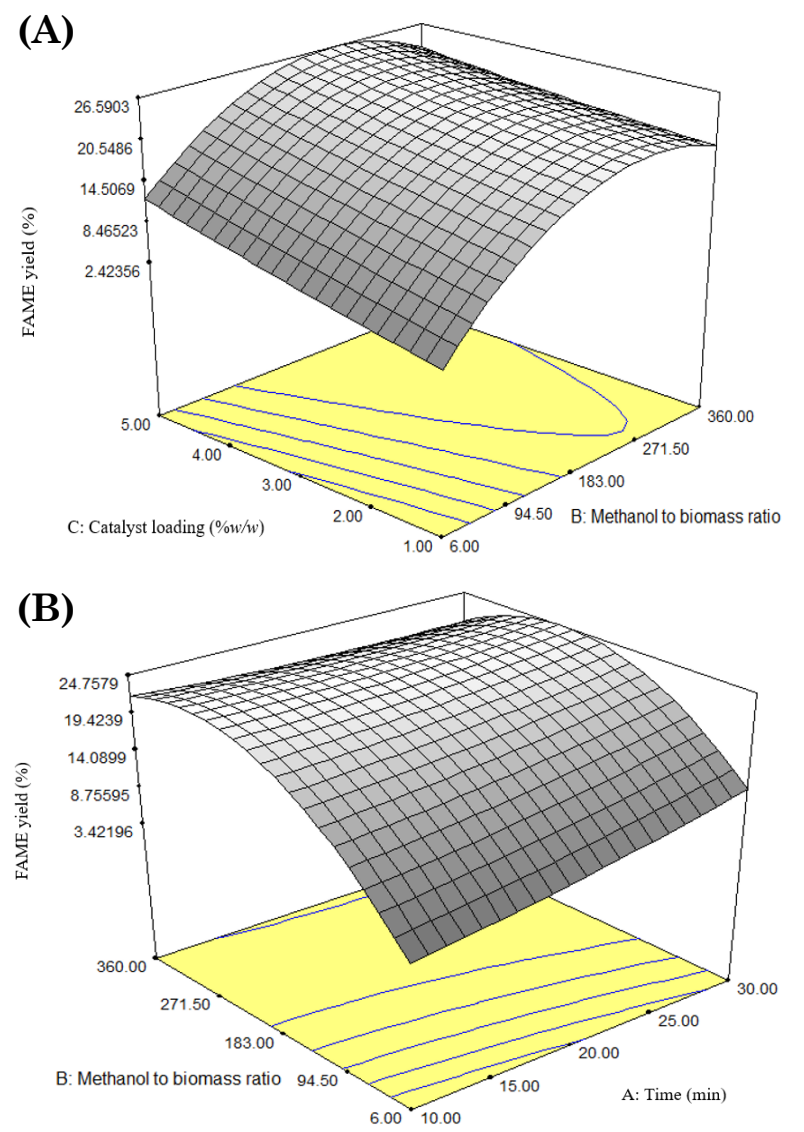

$$
\begin{aligned}
\text { FAME yield } & =21.95+1.63 A+6.85 B+3.38 C \\
& +0.56 A^{2}-8.28 B^{2}+0.36 C^{2}-2.33 A B \\
& +1.37 A C-1.38 B C
\end{aligned}
$$

The model is significant due to the values of "Prob $>F$ " less than 0.0500 and the model $F$ value of 10.25 where only a $0.28 \%$ chance that the model $F$-Value occurred due to noise (Table $6)$. As the $P$-value is the indicator of the significance of each regression coefficient, where the smaller $P$-value will give greater significance of the corresponding coefficient [31]. In this case, the model term of $B, C, B^{2}$ are significant. Table 7 shows the regression model diagnostic from ANOVA. The coefficient of determination or $R^{2}$ is the indicator of how fit the data is represented using the regression line. From the model, the $R^{2}$ is found to be 0.9295 .

Figure 5(a) of three-dimensional plot shows that the increasing in catalyst percentage influenced the FAME yield as the results showed increasing pattern from $1 \%$ until $5 \%$ of the catalyst loading. Figure 5(b) depicts that the FAME yield increased greatly as the methanol to biomass ratio increased. The reaction time was observed to have poor influence on the re-

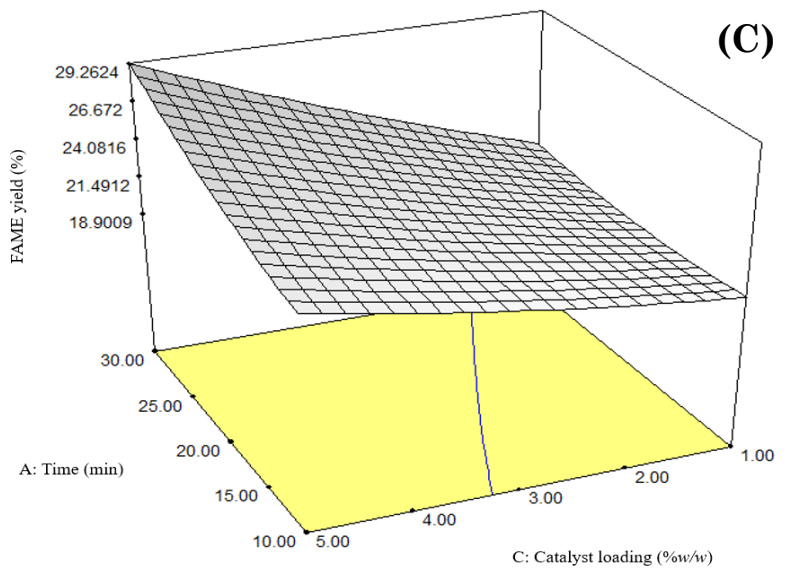

Figure 5. Effect on FAME yield (\%) through the synergy of (a) catalyst loading and methanol to biomass ratio, (b) methanol to biomass ratio and reaction time, and (c) reaction time and catalyst loading.

Table 7. Regression model diagnostic from analysis of variance (ANOVA).

\begin{tabular}{lc}
\hline Regression model diagnostic from ANOVA & Value \\
\hline Std. Dev. & 2.90 \\
Mean & 16.19 \\
C.V. & 17.92 \\
PRESS & 1283.29 \\
$R^{2}$ & 0.9295 \\
Adjusted $R^{2}$ & 0.8389 \\
Predicted $R^{2}$ & -0.5362 \\
Adeq Precision & 10.668 \\
\hline
\end{tabular}


sults of the FAME yield as compared to the other two parameters (Figure 5(c)).

\section{Conclusions}

This study showed that fungi Aspergillus oryzae was able to accumulate lipids from organic carbon source. It has been found that the Bligh and Dyer extraction using chloroform and methanol on fungal biomass of $A$. oryzae resulted in considerably better lipid yield in comparison to extraction by the Soxhlet method using hexane. Comparison study of ex-situ and in-situ transesterification showed the highest FAME yield from base-catalyzed in-situ transesterification at $17.9 \%$. Base-catalyzed in-situ transesterification was optimized using RSM that showed that the maximum FAME yield at $25.1 \%$ was achieved with catalyst loading, methanol to biomass ratio and reaction time at 5\%, 360:1 and 10 min, respectively. The model was significant based on ANOVA.

\section{Acknowledgments}

The authors acknowledge research funding from Ministry of Higher Education, Malaysia under Fundamental Research Grant Scheme (FRGS) (FRGS/1/2019/TK02/UIAM/02/3). The authors would also like to acknowledge Ministry of Higher Education, Malaysia for the Postdoctoral Fellowship scheme of the corresponding author.

\section{References}

[1] Huang, D., Zhou, H., Lin, L. (2012). Biodiesel: an alternative to conventional fuel. Energy Procedia, 16, 1874-1885. DOI: 10.1016/j.egypro.2012.01.287

[2] Roux, J.M., Lamotte, H., Achard, J.L. (2017). An overview of microalgae lipid extraction in a biorefinery framework. Energy Procedia, $\quad 112, \quad 680-688$. D O I : 10.1016/j.egypro.2017.03.1137

[3] Chisti, Y. (2007). Biodiesel from microalgae. Biotechnology Advances, 25(3), 294-306. DOI: 10.1016/j.biotechadv.2007.02.00

[4] Jaikumar, S., Bhatti, S.K., Srinivas, V. (2019). Emission and vibration characteristics of Niger seed oil biodiesel fuelled diesel engine. Journal of Mechanical Engineering and Sciences, 13(4), 5862-5874. DOI: 10.15282/jmes.13.4.2019.11.0467

[5] Thanh, L.T., Okitsu, K., Boi, L.V., Maeda, Y. (2012). Catalytic technologies for biodiesel fuel production and utilization of glycerol: a review. Catalysts, 2(1), 191-222. DOI: 10.3390/catal2010191
[6] Nuhma, M.J., Alias, H., Jazie, A.A, Tahir, M. (2021). Role of Microalgae as a Source for Biofuel Production in the Future: A Short Review. Bulletin of Chemical Reaction Engineering \& Catalysis, 16(2), 396-4123. DOI: 10.9767/bcrec.16.2.10503.396-412

[7] Ahmad, F.B., Zhang, Z., Doherty, W., O'Hara, I. (2016). Microbial oil production from sugarcane bagasse hydrolysates by oleaginous yeast and filamentous fungi. In Proceedings of the 38th Annual Conference of the Australian Society of Sugar Cane Technologists (pp. 251-259). Australian Society of Sugar Cane Technologists-ASSCT.

[8] Ahmad, F.B., Zhang, Z., Doherty, W.O., O'Hara, I.M. (2015). A multi-criteria analysis approach for ranking and selection of microorganisms for the production of oils for biodiesel production. Bioresource Technology, 190, 264273. DOI: 10.1016/j.biortech.2015.04.083

[9] Ahmad, F.B., Zhang, Z., Doherty, W.O., O'Hara, I.M. (2019). The prospect of microbial oil production and applications from oil palm biomass. Biochemical Engineering Journal, 143, 9-23. DOI: 10.1016/j.bej.2018.12.003

[10] Ochsenreither, K., Glück, C., Stressler, T., Fischer, L., Syldatk, C. (2016). Production strategies and applications of microbial single cell oils. Frontiers in Microbiology, 7, 1539.DOI: 10.3389/fmicb.2016.01539

[11] Sitepu, I.R., Garay, L.A., Sestric, R., Levin, D., Block, D.E., German, J.B., Boundy-Mills, K.L. (2014). Oleaginous yeasts for biodiesel: current and future trends in biology and production. Biotechnology Advances, 32(7), 13361360. DOI: 10.1016/j.biotechadv.2014.08.003

[12] Ranjan, A., Patil, C., Moholkar, V.S. (2010). Mechanistic assessment of microalgal lipid extraction. Industrial \& Engineering Chemistry Research, 49(6), 2979-2985. DOI: 10.1021/ie9016557

[13] Scott, S.A., Davey, M.P., Dennis, J.S., Horst, I., Howe, C.J., Lea-Smith, D.J., Smith, A.G. (2010). Biodiesel from algae: challenges and prospects. Current Opinion in Biotechnology, 21(3), $277-286$. D O I : 10.1016/j.copbio.2010.03.005

[14] Sánchez, Á., Cancela, Á., Maceiras, R., Alfonsín, V. (2014). Lipids extraction from microalgae for biodiesel production. In 2014 International Renewable and Sustainable Energy Conference (IRSEC) (pp. 921-924). IEEE. DOI: 10.1109/IRSEC.2014.7059765

[15] Ahmad, F.B., Zhang, Z., Doherty, W.O., O'Hara, I. M. (2016). Evaluation of oil production from oil palm empty fruit bunch by oleaginous micro-organisms. Biofuels, Bioproducts and Biorefining, 10(4), 378-392. DOI: 10.1002/bbb.1645 
[16] Ahmad, F.B., Zhang, Z., Doherty, W.O., O'Hara, I.M. (2018). Optimising extraction of microalgal oil using accelerated solvent extraction by response surface methodology. J. Eng. Sci. Technol., 13, 964-976.

[17] Smedes, F., Thomasen, T.K. (1996). Evaluation of the Bligh \& Dyer lipid determination method. Marine Pollution Bulletin, 32(8-9), 681-688. DOI: 10.1002/lite.200800074

[18] Ríos, S.D., Castañeda, J., Torras, C., Farriol, X., Salvadó, J. (2013). Lipid extraction methods from microalgal biomass harvested by two different paths: Screening studies toward biodiesel production. Bioresource Technology, $133, \quad 378-388$. D O I : 10.1016/j.biortech.2013.01.093

[19] Zhang, X., Yan, S., Tyagi, R.D., Surampalli, R.Y., Valéro, J.R. (2014). Ultrasonication aided in-situ transesterification of microbial lipids to biodiesel. Bioresource Technology, 169, 175-180. DOI: 10.1016/j.biortech.2014.06.108

[20] Laurens, L.M., Quinn, M., Van Wychen, S., Templeton, D.W., Wolfrum, E.J. (2012). Accurate and reliable quantification of total microalgal fuel potential as fatty acid methyl esters by in situ transesterification. Analytical and Bioanalytical Chemistry, 403(1), 167-178. DOI: $10.1007 / \mathrm{s} 00216-012-5814-0$

[21] Prommuak, C., Pavasant, P., Quitain, A.T., Goto, M., Shotipruk, A. (2012). Microalgal lipid extraction and evaluation of single-step biodiesel production. Engineering Journal, $16(5), \quad 157-166$. D O I : 10.4186/ej.2012.16.5.157

[22] Hussain, J., Liu, Y., Lopes, W.A., Druzian, J.I., Souza, C.O., Carvalho, G.C., Nascimento, I.A., Liao, W. (2015). Effects of different biomass drying and lipid extraction methods on algal lipid yield, fatty acid profile, and biodiesel quality. Applied Biochemistry and Biotechnology, 175(6), 3048-3057. DOI: 10.1007/s12010-015-1486-5

[23] Borges, M.E., Díaz, L. (2012). Recent developments on heterogeneous catalysts for biodiesel production by oil esterification and transesterification reactions: A review. Renewable and Sustainable Energy Reviews, 16(5), 2839-2849. DOI: 10.1016/j.rser.2012.01.071

[24] Talha, N.S., Sulaiman, S. (2016). Overview of catalysts in biodiesel production. ARPN Journal of Engineering and Applied Sciences, 11(1), 439-442.

[25] Tanzi, C.D., Vian, M.A., Chemat, F. (2013). New procedure for extraction of algal lipids from wet biomass: a green clean and scalable process. Bioresource technology, 134, 271-275. DOI: 10.1016/j.biortech.2013.01.168
[26] Shin, H.Y., Ryu, J.H., Bae, S.Y., Crofcheck, C., Crocker, M. (2014). Lipid extraction from Scenedesmus sp. microalgae for biodiesel production using hot compressed hexane. Fuel, 130, 66-69. DOI: 10.1016/j.fuel.2014.04.023

[27] Li, Y., Naghdi, F.G., Garg, S., Adarme-Vega, T.C., Thurecht, K.J., Ghafor, W.A., Tannock, S., Schenk, P.M. (2014). A comparative study: the impact of different lipid extraction methods on current microalgal lipid research. Microbial Cell Factories, 13(1), 1-9. DOI: $10.1186 / 1475-2859-13-14$

[28] Wu, L., Wei, T.Y., Tong, Z.F., Zou, Y., Lin, Z.J., Sun, J.H. (2016). Bentonite-enhanced biodiesel production by $\mathrm{NaOH}$-catalyzed transesterification of soybean oil with methanol. Fuel Processing Technology, 144, 334340. DOI: 10.1016/j.fuproc.2015.12.017

[29] Velasquez-Orta, S.B., Lee, J.G.M., Harvey, A.P. (2013). Evaluation of FAME production from wet marine and freshwater microalgae by in situ transesterification. Biochemical Engineering Journal, 76, 83-89. DOI: 10.1016/j.bej.2013.04.003

[30] Gargano, I., Marotta, R., Andreozzi, R., Olivieri, G., Marzocchella, A., Spasiano, D., Pinto, G., Pollio, A. (2016). Alkaline direct transesterification of different species of Stichococcus for bio-oil production. New Biotechnology, 33(6), 797-806. DOI: 10.1016/j.nbt.2016.07.012

[31] Tran, D.T., Chen, C.L., Chang, J.S. (2013). Effect of solvents and oil content on direct transesterification of wet oil-bearing microalgal biomass of Chlorella vulgaris ESP-31 for biodiesel synthesis using immobilized lipase as the biocatalyst. Bioresource Technology, $135, \quad 213-221$. D O I : 10.1016/j.biortech.2012.09.101

[32] Alishah Aratboni, H., Rafiei, N., GarciaGranados, R., Alemzadeh, A., MoronesRamírez, J.R. (2019). Biomass and lipid induction strategies in microalgae for biofuel production and other applications. Microbial Cell Factories, 18(1), 178. DOI: 10.1186/s12934-019-1228-4

[33] Ahmad, F.B., Zhang, Z., Doherty, W.O.S., Te'o, V.S.J., O'Hara, I.M. (2017). Improved microbial oil production from oil palm empty fruit bunch by Mucor plumbeus. Fuel, 194, 180-187. DOI: 10.1016/j.fuel.2017.01.013 